Public Reporting burden for this collection of information is estimated to average 1 hour per response, including the time for reviewing instructions, searching existing data sources,

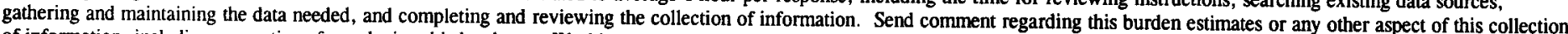

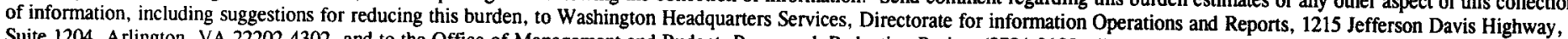
Suite 1204, Arlington, VA 22202-4302, and to the Office of Management and Budget, Paperwork Reduction Project (0704-0188,) Washington, DC 20503.

\begin{tabular}{|c|c|c|}
\hline 1. AGENCY USE ONLY ( Leave Blank) & $\begin{array}{l}\text { 2. REPORT DATE } \\
25 \text { September } 2002\end{array}$ & $\begin{array}{l}\text { 3. REPORT TYPE AND DATES COVERED } \\
\text { Final Report February } 2002-\text { - ty } 2002 \\
\text { Ol }\end{array}$ \\
\hline \multicolumn{2}{|c|}{$\begin{array}{l}\text { 4. TITLE AND SUBTITLE } \\
\text { Proof-of-principle Polymer Engine-Generator }\end{array}$} & $\begin{array}{l}\text { 5. FUNDING NUMBERS } \\
\text { Contract No. DAAD19-02-C-0040 }\end{array}$ \\
\hline \multicolumn{3}{|l|}{$\begin{array}{l}\text { 6. AUTHOR(S) } \\
\text { Ronald E. Pelrine }\end{array}$} \\
\hline \multicolumn{2}{|c|}{$\begin{array}{l}\text { 7. PERFORMING ORGANIZATION NAME(S) AND ADDRESS(ES) } \\
\text { SRI International } \\
333 \text { Ravenswood Avenue } \\
\text { Menlo Park, California } 94025\end{array}$} & $\begin{array}{l}\text { 8. PERFORMING ORGANIZATION } \\
\text { REPORT NUMBER } \\
\text { 11783-FR-02-147 }\end{array}$ \\
\hline \multicolumn{2}{|c|}{$\begin{array}{l}\text { 9. SPONSORING / MONITORING AGENCY NAME(S) AND ADDRESS(ES) } \\
\text { U. S. Army Research Office } \\
\text { P O Rox 12011 }\end{array}$} & $\begin{array}{l}\text { 10. SPONSORING / MONITORING } \\
\text { AGENCY REPORT NUMBER }\end{array}$ \\
\hline
\end{tabular}

The views, opinions and/or findings contained in this report are those of the author(s) and should not be construed as an official Department of the Army position, policy or decision, unless so designated by other documentation.

12 a. DISTRIBUTION / AVAILABILITY STATEMENT

12 b. DISTRIBUTION CODE

Approved for public release; distribution unlimited.

13. ABSTRACT (Maximum 200 words)

Polymer engine-generators have outstanding potential advantages for DoD power generation needs including lightweight simplicity, low cost, great design flexibility, and little or no noise signature. However, the temperature tolerance of the electroactive polymers is a technical risk for such devices. High gas temperatures are needed for high efficiency to be feasible. This project showed that polymer engines could operate successfully using gas temperatures in excess of 1000 $\mathrm{C}$, more than sufficient to produce high potential efficiencies. Over 10000 cycles (the project target) were successfully demonstrated using propane and butane fuels, and much longer lifetimes are undoubtedly feasible. As with a conventional metal engine, the internal gas temperature is very high but the wall temperatures are much lower due to local wall cooling. Thus, wall temperatures are kept safely below polymer operating limits.

14. SUBJECT TERMS

Power generation, electroactive polymers

5. NUMBER OF PAGES 3

6. PRICE CODE

\begin{tabular}{|l|c|c|c|}
$\begin{array}{l}\text { 17. SECURITY CLASSIFICATION } \\
\text { OR REPORT } \\
\text { UNCLASSIFIED }\end{array}$ & $\begin{array}{c}\text { 18. SECURITY CLASSIFICATION } \\
\text { ON THIS PAGE } \\
\text { UNCLASSIFIED }\end{array}$ & $\begin{array}{c}\text { 19. SECURITY CLASSIFICATION } \\
\text { OF ABSTRACT } \\
\text { UNCLASSIFIED }\end{array}$ & $\begin{array}{c}\text { 20. LIMITATION OF ABSTRACT } \\
\text { ULL }\end{array}$ \\
\hline NSN 7540-01-280-5500 & \begin{tabular}{c} 
UNA \\
\hline
\end{tabular}
\end{tabular}




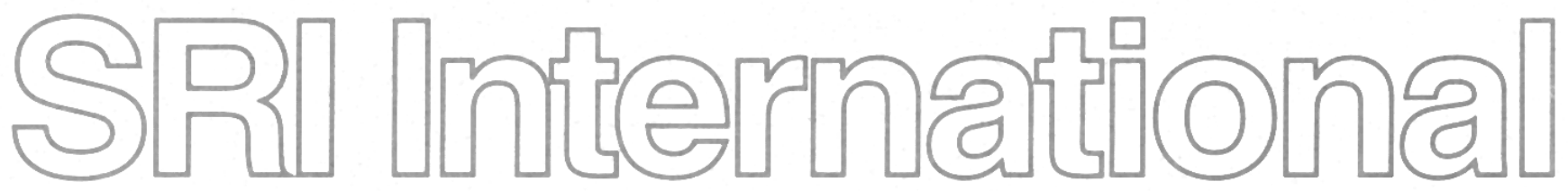

Final Report • September 2002

Covering the Period of February 2002 - July 2002

\section{PROOF-OF-PRINCIPLE POLYMER ENGINE-GENERATOR}

ITAD-11783-FR-02-147

SRI Project 11783

Contract No. DAAD19-02-C-0040

Prepared by

Ronald E. Pelrine, Program Director

Advanced Automation Technology Center

Prepared for

Defense Advanced Research Projects Agency

3701 North Fairfax Drive

Arlington, Virginia 22203-1714

Attention: Dr. Valerie Browning

and

U.S. Army Research Office

P.O. Box 12211

Research Triangle Park, North Carolina 27709-2211

Attention: AMSRL-RO-BI (IPR)

Approved by

Prasanna G. Mulgaonkar, Director

Advanced Automation Technology Center 


\section{Proof-of-Principle Polymer Engine-Generator}

SRI International (SRI) is pleased to submit this final report, ITAD-11783-FR-02-147, on SRI project EMU 11783, Proof-of-Principle Polymer Engine-Generator, to the Army Research Office (ARO) and Defense Advanced Research Projects Agency (DARPA).

\section{STATEMENT OF THE PROBLEM STUDIED}

The objective of the project was to demonstrate the feasibility of using high-temperature expanding gases to drive an electroactive polymer (EAP) element for producing electricity. This proof-of-principle project is not intended to produce an efficient polymer engine-generator, but rather to show that the polymers can operate using high temperature gases where high efficiency is theoretically possible. Polymer engines have numerous potential advantages such as light weight, simplicity, quiet operation, low cost, and excellent design flexibility, to name a few. However, prior to this project good efficiency was a major technical risk with polymer engines because of their uncertain temperature tolerance. The results described below greatly reduce, or, at the levels tested, eliminate this risk.

\section{SUMMARY OF THE MOST IMPORTANT RESULTS}

The project produced several important results. First and foremost, we demonstrated that electroactive polymers could operate using high temperature combustion gases for extended periods of time. Using an internal combustion approach, we demonstrated gas temperatures well over $1000{ }^{\circ} \mathrm{C}$, well in excess of those needed to produce good theoretical efficiency. Three fuels were successfully demonstrated: propane, butane, and hydrogen. The combustion chamber was formed from an EAP diaphragm that expanded when the fuel-air mixture was fired by a small spark. As with a conventional metal engine, the internal gas temperature was very high, but the chamber's wall temperature was safely below the damage threshold because the polymer could absorb the transient heat pulse without overheating. Figure 1 shows one of the proof-of-principle engines during propane combustion. In this figure, the EAP diaphragm is somewhat difficult to distinguish, but its curved surface can be discerned by the light reflection indicated by the arrow. Note that the blue light issuing from the diaphragm is due to the propane combustion.

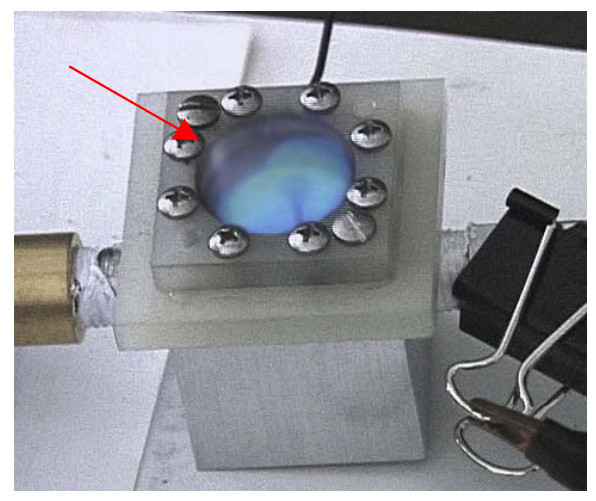

Figure 1. Proof-of-Principle Polymer Engine During Propane Combustion 
Analysis indicated that a polymer engine might be competitive with rechargeable batteries capable of powering as few as 5000 cycles. The polymer itself is so low cost that it could be used as a disposable item, although current data indicates that the polymer can survive for such long periods of time that it may be permanent. The project set a goal of 10,000 engine firings; this goal was achieved with both propane and butane fuels. Firing of only up to 1000 cycles was demonstrated with hydrogen fuel because of spark-plug wetting issues unrelated to the polymer material. In each lifetime test case the polymer was intact at the end of the test, even though area strains of $100 \%$ (an attractive strain for EAP generators) were shown during expansion. Since this small project was focused on gas temperatures and not power production per se, we did not attempt to produce high power output. However, using butane we showed the polymer engine producing small amounts of power with an input voltage of $300 \mathrm{~V}$ and an output voltage of $1400 \mathrm{~V}$ for 10,000 cycles.

Little to no damage was observed on the films. In some tests a few small pits were observed in non-electroded (bare) films. However, it is not certain how the pits were produced, and in any case they were insufficiently deep to puncture the thin, $70-\mu \mathrm{m}$ film under tension. The pits may have been caused by heat damage, by tiny particles accelerated by the combustion, or by too rapid expansion of the particular polymer used. ${ }^{1}$ No pits were observed in electroded films, which may have been due to the carbon-based electrode protecting the inner layer of film. Note that even pits that go part way into the film would typically cause an electrical breakdown at $1400 \mathrm{~V}$, but such breakdowns did not occur in the energy production test. Thus, whatever their cause, the small pits are not expected to be an issue for the polymer engine and can be prevented by a thin, passive inner layer or just an inner electrode, or by using dust-free fuel or a polymer with lower viscoelasticity in cases where the pits are caused by dust or too high viscoelasticity.

Given the success of the internal combustion tests, the project did not explore external combustion methods in detail. We did demonstrate a simple liquid piston device that isolated the EAP from boiling water at the end of a connected tube.

In conclusion, the project successfully showed that a polymer engine can withstand combustion gases at sufficiently high temperatures to achieve attractive efficiencies. Though much work remains to be done to achieve high efficiency in a practical polymer engine, this work has established the basic feasibility of such a goal.

\section{PUBLICATIONS}

No documents were published in the course of the project.

\section{PARTICIPATING SCIENTIFIC PERSONNEL}

The following scientific personnel participated in the project.

- Dr. Ron Pelrine

- Dr. Seajin $\mathrm{Oh}$

- Mr. Roy Kornbluh

- Dr. Qibing Pei

\footnotetext{
${ }^{1}$ This polymer is only rated up to $100{ }^{\circ} \mathrm{C}$, unlike other EAPs that are rated up to $150-300{ }^{\circ} \mathrm{C}$. Furthermore, the polymer used has relatively high viscoelastic losses, so the pits could have been caused by too rapid mechanical expansion.
} 
- Mr. Neville Bonwit

- Mr. Surjit Chokar

- Mr. Harsha Prahlad.

\section{REPORT OF INVENTIONS BY TITLE}

No inventions resulted from the project. 